\title{
Values-directed enterprise engineering ${ }^{1}$
}

\author{
Evgeny Z. Zinder \\ Chairman of the Board, NCO "Foundation for System Engineering, \\ Standardization and Project Management Support” (FOSTAS Foundation) \\ Address: Mailbox 563, Moscow, 107061, Russia \\ E-mail: ezinder@fostas.ru
}

\begin{abstract}
This article presents an approach to enterprise engineering (EE) enhancement under modern conditions by including in EE possibilities and capabilities of systematic decision making support based on the values analysis of an enterprise and all the engaged parties - stakeholders of different categories. The particularity of the approach consists of combining broad understanding of values, aiming at real business tasks at all the levels of enterprise management, and including digital transformations risk management in these tasks.
\end{abstract}

The approach includes both "analog" and "digital" values models, and also employs heterogeneous values models. Values are regarded as a social and economic, corporate and personal phenomenon. Subjectivity, situatedness, relativity, and changeability of values are taken into consideration. The article suggests conjoint consideration of various stakeholders' (interested parties') heterogeneous values, among others, of stakeholders affected by digital transformations. The enterprise itself as an economic agent, its owners, employees, enterprise-partners, clients/customers, communities, social organizations, and public agencies might be among the stakeholders considered One of the key requirements is values comparability and the ability to determine the gap between different stakeholders' values. Other requirements define the constitution of values models and characteristics of models elements.

One of the essential results of this research is the developed system of requirements. Besides, the structure of an open multidimensional enterprise values space is suggested as well as the structure of partial and integrated values models placed in this space is presented. The framework for tracing relations between the enterprise components and the stakeholders' values is proposed, and the possibility of introducing functions assessing conformity and nonconformity of different stakeholders' values on the integrated values model of the enterprise is demonstrated. The presented system of requirements and models enables building and applying values models which was tested in completed projects. The approach allows enabling sustainable enterprises development under digital economy conditions at the fundamental level by values-directed management. Moreover, , it might prove useful for expanding various enterprise transformation methods, including their existing value-directed and value-centered variants.

Key words: enterprise engineering; digital transformation; values; values model; risk management; values space; values-directed enterprise engineering; digital values model; analog values model.

\footnotetext{
${ }^{1}$ This work was supported by the Russian Foundation for Basic Research (project No. 16-07-01062

"Development of methods and resources of enterprise engineering based on smart technologies")
} 
Citation: Zinder E.Z. (2018) Values-directed enterprise engineering. Business Informatics, no. 3 (45), pp. 7-19. DOI: 10.17323/1998-0663.2018.3.7.19.

\section{Introduction}

$\mathrm{D}$ iscussions about the "digital economy" concept and recommendations for "digital transformations" (DT) [1] go on along with reports of hacking systems formerly claimed invulnerable, of limitations of artificial intelligence services, and of business models banned judicially [2]. This turbulence forces us to search for approaches to preservation of valuable features of enterprises under changing conditions, and in DT realization in particular. This publication offers a way of enterprise engineering (EE) aimed at sustainability of enterprise development and enabling actualization of various DT methods. This refers, in particular, to well-known methods such as value-oriented (for example, [3; 4]) and value-centered (for example, [5;6]). The proposed approach builds upon broad understanding of values in contrast to its submission to one particular theory and aims at solving a wide range of business tasks including tasks of DT and sustainable development, as well as tasks of risk management in transformation of enterprises and society in a turbulent digital economy environment. Metamodels for "analog" and "digital" values models are suggested for practical support of this approach; possible directions and examples of their application are provided. Further on, this approach will be called "Values-directed enterprise engineering." This name is believed to be relevant to the vitally important, all-pervading role of values in socio-economic, organizational, managerial, production, and even bio-information $[7 ; 8]$ processes.

The rest of the paper is structured as follows. Section one presents basics and the purpose of this paper and formulates the main requirement R1 for values modeling. Section two describes the features of values as a phenomenon and their use in the enterprise business tasks, establishes the necessity of more sense bearing values models than those employed in many works on EE, suggests a working definition of values for the given context, and formulates corresponding requirements R2-R5. Section three defines the requirements R6R9 for singled out features and elements of the general values model structure corresponding to requirements R1-R9, multidimensional Open Enterprise Values Space (OEVS), the rules of formalizing an Open Integrated Values Model (OIVM) of enterprise and its stakeholders. The Conclusion discusses some options for using the proposed rules and models and indicates directions for further research and development.

Note: Stakeholder in this article is understood as an interested party of any type connected with an enterprise being analyzed and its digital transformation, including the enterprise itself as an economic agent.

\section{Beginnings of this study and the primary requirement for values models}

Mentioned in the Introduction, turbulence of the digital economy prompted us about a year ago to publish our analysis of the situation with respect to the development of conceptions and main EE methods [9]. This showed that the existing EE paradigm retains its efficiency in the face of radically changed organizational structures, communications, and working processes. An assumptive reason is that the basic enterprise features like mission and responsibility for producing some goods or service persist. At the same time, new abilities of DT require more careful tracing of the main guiding lines of enterprise development 
and paying more attention to possible threats described in the reports $[1 ; 10 ; 11]$ as well as to still unknown threats. The need for concrete methods to satisfy these requirements induced additional studies and served as a prerequisite to this publication. Formerly, we described additional studies and their main recommendations for the following areas:

$\uparrow$ continuous strategic and tactic enterprise governance [12];

\ knowledge management in dynamically changing network business processes and cooperation and co-creation processes [13];

$\checkmark$ risk management in enterprise DT projects $[14]^{2}$.

Each of these studies revealed that values of individuals, their communities, and organizations play a significant or even a leading role as development guiding lines and decision making criteria in various EE key tasks, as well as in day-to-day enterprise activity. Meanwhile, values should be interpreted both broadly and in detail, including humanitarian and economic aspects, because working with the guiding lines requires comprehensive analysis of all essential aspects of an enterprise constitution and activity.

For this reason and according to the restriction of values models mentioned in sub-section 2.1 and their application in known formal models descriptions for EE, the author analyzed values as a phenomenon, examined areas of application of values descriptions at enterprises, formulated a set of requirements to values models associated with an enterprise, and defined a constructive approach to formalized modeling of values and their systems. The primary requirement for values models is:
R1. Values models must be applicable for comprehensive definition and control of enterprise development guiding lines as well as emerging risk management, including guiding lines and risk management in DT projects and functioning of transformed enterprises.

\section{Values phenomenon analysis and requirements for values modeling}

\subsection{Value as a phenomenon} and the basis of values models formalization

The analysis and description of human values has a long history [15]. We take this history into account and proceed to present tasks combining different views on values as a social, corporate, and personal phenomenon.

Work with values in a broad sense while forming corporate culture has long been put into practice and stated at the level of course books [16]. However, significant progress in structuring, comparing, and formalizing values models can be noticed when working with value as a cost or as a feature well expressible in a monetary form $[17 ; 18]$, which is not enough for satisfying $\mathrm{R} 1$.

The significance of using values as a reference point in EE is recognized by many authors [3-6; 19]. However, in the known attempts of values formalization in EE, interpretations significantly constraining the real phenomenon are employed. For instance, papers [3; 19] inherently consider values within the scope of only one EE theory but not from the point of view of exploring values in real life of enterprises with the subsequent implanting of results of the exploration in EE theory. Besides, this value model appears extremely simplified and is primarily used for reflecting exchanges

\footnotetext{
${ }^{2}$ The paper [14], in particular, is based on the author's studies 2012-2018 where the analysis of risks and risk management methods in applying new technologies were conjoined with systematic discussions of these risks and methods in various projects and professional groups. In particular, in 2017, such risks and methods were demonstrated and discussed on the video channel "Cyber-tech" https://www.youtube.com/watch?v=6KTG9brsiNU\&feature=youtu. be (accessed 05 July 2018) and at the round table "Risk management in the digital age" in Plovdiv, Bulgaria (23 November 2017)
} 
between actors. The approach in [4] takes into consideration various points of view on values, including their nonmonetary and emotional categories to a greater extent and suggests a value metamodel taking into account actors' values of different types. However, in the context of the requirement $\mathrm{R} 1$, this model also appears too restricted. In particular, only two types of stakeholders are considered (the service's supplier and client), and their interconnection reflects only their interaction in a co-creation style. Values models in these cases are not expected to be appropriate for solving a wide range of business tasks in which values of public and humanitarian categories play an essential role.

Comprehensive analysis and treatment of social and humanitarian values appears more complicated. Due to this, specific methods and approaches are developed, such as, for instance, "management by values" [20], expanding complex management schemes of different scales by including humanitarian values, up to the highest spiritual values [21]. Suggestions appear simultaneously to transform the values complex of various types into some economic entity reflecting an enterprise sustainability [5], as it is supposed that businesses could be motivated to make meaningful changes only in such a case. At the same time, the use of non-formalized "analog" values models for different stakeholders' categories and their application in various business tasks, including those different from the tasks of values exchange, in particular, in risk management tasks [6], remains actual and topical.

On the whole, there is no generally accepted, sufficiently complete, and at least partially formalized metamodel of values, and comparing values is very difficult due to a number of contradictory approaches to the interpretation of the very concept of value.

Significantly, a huge number of non-formalized models have been accumulated within axiology, including models treating various aspects of values [22; 23]. These models are important, as practically any aspect might be essential for solving a specific business task. However, attempts at direct use of values in their conventional forms face the serious problem of the diversity of values manifestations. In concrete situations, any feature of a material or ideal entity can be recognized as a value. Values can be divided into values-tools (means) and values-goals [16], and be ordered differently according to priorities, and such evaluations are quite subjective and changeable. As a result, the most significant feature of the existing situation is acknowledgment of subjectivity, situatedness, relativity, and changeability of values of different interconnected parties - the enterprise stakeholders. In particular, we point out the extremely high rate of change in the picture of the world and the fact that these changes are crucial in the values variability. For instance, it was shown in [24] that, for new generations this factor leads to inverting of value systems relative to those that were considered conventional not long ago.

As mentioned in the New Philosophic Encyclopedia [22], there is methodological chaos even in the definition of the value concept and in the treatment of value relations. It seems that this chaos only means that unitary values models structured and ordered each in its own way, as was done earlier, are not suitable for reaching the complex goals mentioned above. Pragmatic ways of building and applying values models should work in real "chaotic" conditions, while remaining understandable to different people and engaged in the context of enterprise "digital life," and all this leads to the requirement $\mathrm{R} 2$ :

R2. It is necessary to combine forming and using values models of both the "analog" type, that is, oriented to traditional ("manual") ways of using them in enterprises, and of the "digital" type, that is, formalized for enabling their com- 
puter processing in a computerized ("digital") information environment of enterprises. In this case, "analog" and "digital" models of the same single value should not contradict each other in terms of their semantics.

\subsection{About the role of common highest values and about a working definition of values}

Recognizing the existence and common interpretation of some highest values by various stakeholders provides the foundation for solving many practical problems, including reaching a compromise when other common interpretations of values are missing, and forming a working definition of a value given below:

"Value is understood as the boon to an individual, a group, enterprise, and/or a society in the sense of moving towards highest values or in terms of protecting them from a shift in the opposite direction."

We discussed this and similar interpretations with different audiences. We had very important conversations with Dharia Rahi GuruMata, Head of the International Department in the ashram Atma Kutir ${ }^{3}$. The boon was discussed in two incarnations: as a high ethical category and as progress towards this category in everyday life, including activities of enterprises. The subjective nature of the evaluation of the boon was taken into account, and accordingly, the needs and ways of performing expert assessments of the availability of the boon and its relative scope were discussed.

The author fully recognizes that interpretations of highest values of different stakeholders can be dramatically contradicting each other. However, our times show real possibilities for a strong rapprochement between the positions of various ethical and spiritual teachings which can be caused by the awareness of the increase in common threats in all aspects (ecological, technological, and other threats). The report [11] indicates that today, and in the nearest future, universal highest values are earnestly needed to focus on the boon for all living beings and the world as a whole. This leads to the requirement R3:

R3. The values modeling approach must provide for the possibility of encompassing highest values relevant as the common highest values at this historical stage.

\subsection{Aiming values models at business tasks solving}

Details of values models and characteristics of these details are derived from understanding the needs of the models use for a wide range of practical business tasks executed in the area of EE and DT. Requirements induced by two sample groups of business tasks of enterprise transformation and functioning were explored in this study. Later they were generalized for expansion and use in other tasks and formulated as the requirements R4 and R5.

The first example includes typical business tasks of different scales:

$\downarrow$ formation of the enterprise development strategy, including comparison of enterprise DT directions;

$\downarrow$ search for the enterprise's future products (services) on the basis of forecasts of prospective values of customers and promising technologies;

$\downarrow$ testing job applicants for the concordance of their values-tools and those necessary for completing certain jobs.

The second example refers to using values

\footnotetext{
${ }^{3}$ Information about Atma Kutir Ashram (Garval Himalaya, India) is available at http://atmakutir.blogspot.ru_
} 
models in the sphere of risk management which was considered essential in [6]. The approach to risk management for the DT area suggested in [14] is based on:

$\downarrow$ architectural analysis of the enterprise and finding connections between the enterprise components and the values these components really support (so-called traceability to real rather than declared values);

$\checkmark$ comparing this values set to stakeholders' (including clients and enterprise employees) value systems and finding correspondence and possible contradictions.

In both examples, comparing values of different stakeholders and, in some cases, reaching a compromise based on values convergence are required for solving the mentioned tasks. For this purpose, it is necessary to use comparable values models of different stakeholders, in particular, in order to evaluate the concordance of values inherent for stakeholders planning DT and other stakeholders' values. This is reflected in the requirements $\mathrm{R} 4$ and $\mathrm{R} 5$ :

R4. The set of an enterprise values models must present a set of potentially heterogeneous values for all kinds of stakeholders, including those affected by DT, among those, an enterprise as an agent of the economy, its owners, employees, partners, clients, social organizations, and public authorities.

R5. While executing an enterprise tasks, it is reasonable to employ a single space of dimensionality for all possibly heterogeneous values models of different stakeholders' types corresponding to a wide range of elicited business tasks. This space should support the definition of values comparability and the ability to compare them basing on greater-less relation.

Let us call the dimensionality space mentioned in the requirement R5 the "open enterprise values space (OEVS)".

\section{Requirements for values models structure and elements}

\subsection{Traceability of the components of an enterprise to values models}

It is necessary to compare factual values created by the enterprise components, their transformations, and an enterprise as a whole with the enterprise stakeholders' values. For this purpose, in turn, it is necessary to ensure traceability ${ }^{4}$ of relations from the components of the enterprise architecture (including its behavior) to the models of the enterprise and its stakeholders' values which are included in an open integrated values model (OIVM). This leads to the requirements R6 and R7.

R6. An integrated values model of an enterprise must facilitate traceability from any enterprise system component via enterprise goals (or even skipping goals) to the values of all the stakeholders.

R7. Comparable values models must have measurable elements of the same type to compare different stakeholders' values and to support execution of EE and DT tasks. The measures of these elements must be determined by the same or compatible metrics. Comparison of these elements must be done for checking equal or not equal and greater or less relations. The exact differences must be calculated when possible.

For the tracing mentioned in R6, we use the expanded five-model DT scheme proposed in [9]. Table 1 shows the conception of the relationships between the proposed models (line " 1 ") of partial (column " 1 ") and integrated (column " 2 ") values on the one hand and architectural models in the five-model scheme of the functional architecture on the other hand, which includes services or platforms for business functions (line " 3 ") and their business purposes in terms of supported goals (line " 2 ").

\footnotetext{
${ }^{4}$ Traceability and tracing are understood similarly to ISO/IEC 15288 "Systems and software engineering. System life cycle processes"
} 


\section{Framework of tracing from components of a five-model scheme of an enterprise transformation to values models}

\begin{tabular}{l|l|l} 
& \multicolumn{1}{|c|}{$\begin{array}{c}\text { 1. For single party } \\
\text { or component of enterprise }\end{array}$} & \multicolumn{1}{c}{$\begin{array}{c}\text { 2. For integrated representation } \\
\text { of enterprise }\end{array}$} \\
$\begin{array}{l}\text { 1. Values } \\
\text { (see Section 2) }\end{array}$ & Model of value $v_{q n}$ for stakeholder $s_{q}$ & OIVM $=\left\{v_{q n}\right\}$ \\
\hline $\begin{array}{l}\text { 2. Goals (see [9], } \\
\text { Fig. 1) }\end{array}$ & $\begin{array}{l}\text { Business goals and goal indicators achieved } \\
\text { through a specific system or DT component }\end{array}$ & $\begin{array}{l}\text { Integrated business goals indicators system; } \\
\text { their links with OIVM and OICA }\end{array}$ \\
\hline $\begin{array}{l}\text { 3. Components } \\
\text { of DT (see [9]) }\end{array}$ & $\begin{array}{l}\text { Model } c_{t} \text { for a component of enterprise } \\
\text { or DT }\end{array}$ & OICA $=\left\{c_{t^{\prime}} ; c_{t} \times c_{p} \mid p \neq t\right\}$ \\
\hline
\end{tabular}

In this table and hereinafter:

$v_{q n}$ is the specific value for the stakeholder $s_{q}$ from the set $\mathrm{S}$ of all the stakeholders of the enterprise;

OIVM is Open Integrated Values Model which includes all meaningful $v_{q n}$ related to the enterprise;

$c_{t}$ and $c_{p}$ are the high level architectural models of the specific enterprise components;

OICA is Open Integrated Component Architecture which integrates all the enterprise components $c_{t}$ (primarily the business functions and digital services and platforms supporting them) and their relationships.

\subsection{About the heterogeneity of values of different stakeholders}

Values subjectivity and situatedness leads to the possibility of incomparability of two values of the same kind and named equally by two stakeholders due to these values' different contents, for example, if the stakeholders are from different social environments or just belong to different generations.

Example: Different forms of interest for the same kind of values in a digital society. The common values category "Prestige" (at level 4 "Respect" according to [25]) can be inter- esting in the form "Prestige as the $h$-index of the citation", and (for other or same conditions and/or demographic groups) - in the form "Prestige as a number of Likes and Followers in social networks". These two "Prestige" values are formally incomparable in these two forms of interest as their meanings are defined in different domains of definition.

Notes: 1) Both forms of interest can be used by the same stakeholder as two different specific values of one kind; 2) Domain of definition is referred to as "domain" further in this article.

Another example. Loyalty to one's patron and social group (layer) is an essential value in the environment called "Absolute monarchy with the patrons' hierarchy," but it might not be recognized as a value or might even have a negative value in the environment called "Liberal democracy with a market economy."

These examples demonstrate that to be comparable two values must be defined on the same domain determined by the set of the same value categories. In the given example, they must belong to the values of the same socialeconomic environment, the same needs category, and the same form of interest. All this is reflected in the requirements $\mathrm{R} 8$ : 
R8. Values models have to include the elements showing that the values are defined on the specific domain; and accordingly, OEVS has to include the dimensions determining the categories of values, their environments and forms which identify these domains. These dimensions have to enable checking that the various stakeholders'values pairs belong to the same domain and, thus, enable their comparability and homogeneity in this sense.

\subsection{Metrics of values meanings}

Comparable values models defined on the same domain of values can differ due to the realization level for the specific values kind and form of interest. For instance, they can differ in the $h$-index of the citation, information safety index, in the level of the company's (or its employee's) responsibility, and the like.

One suppositive example is a generalized value-tool "Ability to do something" and the realization levels of this ability. For example, "1" = "no ability", "2" = "limited ability", " $3 "=$ "ability in most situations", "4" = "the highest ability." Such metrics are common in completing qualitative assessments of different objects' states. With the consideration of R7 and $\mathrm{R} 8$, this is expressed in R9:

R9. For every domain of the values of the same kind and the same form of interest, it is necessary to design the metric of the realization level for specific values reflecting, when possible, ordered values meanings from the point of view of a stakeholder as a person defining and expressing these values.

\section{Notes:}

1) As a metric, a scale of qualitative levels, a physical indicator of the level, a composite index, or another parameter can be used together with the rules of measuring a realization level of values in this metric and with the rules for comparing different values by this metric.
2) In many cases, it is the difference of realization levels of two values of the same kind and form of interest that leads to the values conflict and accordingly to the conflict of the enterprise components or decisions supporting this value kind or form of interest.

\section{Instantiation and formalization of the values model and values space}

The aforesaid requirements and rules for describing values models along with the rules introduced below in subsection 4.1 can be used in "as is" style as metamodels for forming textual and minimally structured "analog" values models. Meanwhile, the formal description of the values space OEVS following the scheme provided in subsections 4.1 and 4.2 establishes the metamodel of the specific values formalized "digital" models, as in this case values models are considered to be the points in OEVS and have to be formed according to its dimensions and other defined requirements.

\subsection{Partial values models as the basis for OEVS dimensions}

In order to meet the requirement $\mathrm{R} 8$, it is possible to establish OEVS dimensions by categories sets which allow anchoring domains of values in practice. A possible variant of such a categories-determinants set for establishing the dimensions is provided below:

^ the categories (levels) of stakeholders' needs;

$\downarrow$ the categories (levels) of external conditions of stakeholders as their social-economic environments;

$\downarrow$ the categories of stakeholders' behavior in the external environment;

$\downarrow$ values kinds of stakeholders and the levels of their realization according to the requirements R7 and R9;

$\downarrow$ forms of interest for values of the specific kind. 
The kind of the values is traditionally prescribed by its conventional short name (such as, for example, health, honesty, responsibility, and work quality) as well as by its meaty description. The forms of interest for specific value representations depend significantly on the values kind, and these forms might also depend on the domains in other OEVS dimensions.

The OEVS variant suggested below is based on the categories-determinants explicitly or tacitly suggested in the partial models [25-27] and their extensions. These models were selected for the OEVS variant presented due to their wide enough spreading over considerable time and due to the possibility of their extension and adaptation.

In order to fulfill the $\mathrm{R} 8$ requirement for the simultaneous coverage of various stakeholders' values, OEVS must also have the dimension $\mathrm{S}=\left\{s_{q}\right\}$, where $s_{q}$ denotes the coordinate of the particular stakeholder in the OEVS space.

The Maslow model usage. For the A. Maslow model [25], the relativity and variability of the order of the "need/value" levels arising due to different priorities in the satisfaction of different needs for different actors are recognized. The extension [28] which includes additional levels of needs/values: cognitive, aesthetic, values of self-realization and transcendental values, including altruistic values is taken into consideration. Altruistic values can be accepted as a kind of highest values mentioned in R4. This model is used in OEVS as the basis of the dimension $\mathrm{M}=\left\{m_{i}\right\}$ where $m_{i}$ is the level in the "extended Maslow pyramid."

For the specific business task, the dimension $\mathrm{M}$ can be detailed by defining sub-levels for $m_{i}$. Besides, it is possible to introduce one or another relation of order for particular conditions and tasks (for example, the Maslow's original order or the inverted order similar to [24]).

The Graves model usage. The $\mathrm{C}$. Graves model (the "open theory") [26] is applied in both original (simplified in our view) and expanded modes. In a simplified version, the model is used in full accordance with its original scheme as an ordered sequence of development levels of the socio-economic environment joined with the type of the stakeholders' behavior defined as rational for this environment. In order to comply with the described business tasks, the levels of the environment with Graves codes DQ, ER, FS are primarily used. Such a model is used in OEVS as the basis of the dimension $\mathrm{G}=\left\{g_{e}\right\}$, where $g_{e}$ is the development level of the environment and of the stakeholders' behavior in it. In the expanded mode, it is taken into account that the environment and the stakeholder's behavior may not correspond to each other in the manner defined in [26] (an individual can choose an irrational in the view of [26] type of behavior). Taking this into account, such a mode of the partial model induces two dimensions of the OEVS:

$\downarrow$ dimension $\mathrm{G}=\left\{g_{e}\right\}$, where $g_{e}$ is the level of development of the medium,

$\downarrow$ dimension $\mathrm{B}=\left\{b_{h}\right\}$, where $b_{h}$ is the level of the behavior of the stakeholder.

The Schwartz model usage. For each value in OEVS, it is necessary to provide the connection of the levels of $m_{i}, g_{e}$, and $b_{h}$ defined above with a description of the value of a specific kind. The mentioned value description is extended by the actual form of interest for the specific value representation and by measurable levels of the value realization in this form. This extended description, combined with the scales of values realization levels, is used as the basis for the aggregated dimension $\mathrm{SH}$ for description of OEVS values.

In the EOVS version presented, the S. Schwartz model ("the theory of basic values") [27] expanded and supplemented with the above-mentioned method is the basis for the aggregated dimension $\mathrm{SH}=\left\{s h_{j j k}\right\}$, where $s h_{j f k}$ is the combination of the elements:

$\downarrow$ identifying the conventional name of the value kind (for example, "working responsibility") and its generalized description; 
$\checkmark$ the form of interest (in this example, it is the fixation of the fact that a stakeholder holds the characteristic of "working responsibility" expressed in one of the word descriptions predetermined for this kind and form);

$\downarrow$ the level number from the scale of implementation levels for the values of this kind and form with the meaty levels interpretation (in this example, it is the level number in the scale of work responsibility with word description of characteristics of this level responsibility).

\subsection{Values models and an open enterprise values space. An open integrated model of values and values metrics}

Versions of values space OEVS and values models for the whole enterprise OIVM based on the version of values models structuring and formalizing described in subsection 4.1 are presented below.

Open enterprise values space OEVS and values models. OEVS is formed by the set of points $v$-potential values with coordinates:

$\downarrow$ in the simplified version, $v=\left(s_{q}, m_{i}, g_{e}\right.$, $s h_{j k k}$, which provides a way for visual illustrations making;

$\downarrow$ in the extended five-dimensional version, $v=\left(s_{q}, m_{i}, g_{e}, b_{h}, s h_{j k k}\right)$, with a potential increase in the number of dimensions up to six or seven in the case of splitting $\mathrm{SH}$ dimension.

Here every value $v_{q n}$, where $n=\left\{1, \ldots, \mathrm{N}_{q}\right\}, \mathrm{N}_{q}$ is the number of different values of the stakeholder $s_{q}$ from the set of stakeholders $\mathrm{S}$, is represented by a point $v$ with above-mentioned coordinates.

Open integrated values model of an enterprise OIVM. The value set of the stakeholder $\mathrm{S}_{q}$ from the set of stakeholders $\mathrm{S}$ is formed as his or her value system $\mathrm{V}_{q}=\left\{v_{q n}\right\}$, where $n=\left\{1, \ldots, \mathrm{N}_{q}\right\}, \mathrm{N}_{q}$ is the number of different values of this stakeholder.

The Open Integrated Values Model (OIVM) of an enterprise is defined as the set of essential values models of the stakeholders of the enterprise and its DT (including customers as part of the enterprise ecosystem).

That is, OIVM $=\left\{\mathrm{V}_{q}\right\}$, where $q=\{1, \ldots, \mathrm{Q}\}$, $\mathrm{Q}$ is the cardinality of the set of stakeholders $\mathrm{S}$, and all the $\mathrm{V}_{q}$ are defined in the same OEVS. This provides an opportunity to match the values of different stakeholders and to determine their conformities or contradictions to each other.

Values metrics. Realization levels of certain values can be expressed in natural units of measurement (for example, "time spent on receiving a service," "the number of "likes," etc.). For other values, the level of realization is expressed as a qualitative assessment, for example, the ordination number of the conditional realization level with the semantic description of the value realized at this level (see the example in subsection 3.3).

Development of such metrics is performed with each extension of the open scheme of OEVS and the values models in it, among others, for emerging new forms of interest in the $\mathrm{SH}$ dimension. This makes it possible to form and accumulate knowledge about values meanings so that during the EE running it is possible to gradually increase the automation level of intelligent analysis, among others for enterprises DT planning.

\section{Conclusion}

Derived models and functions for completing business tasks. For completing specific business tasks of an enterprise development, in particular, for evaluating its DT acceptability, it is useful to create and apply derived and adapted models on the basis of integrated OIVM and OICA (Table 1). For risk management in DT, for example, it is important to analyze the compatibility of pairwise combinations of the values which can contradict each other. In particular, this is done for evaluating combinations of the enterprise values as val- 
ues supported (or disappearing because of a component exclusion) by specific functional components $c_{t}$ on the one hand, and values of enterprise employees, customers, and regulating agencies' values on the other hand, which is described in [14].

In order to formalize such an assessment, it is recommendable to define function $F\left(c_{t}, v_{q_{1}{ }^{n}}, v_{q_{2^{n}}}\right)$ versions which give, for example, the assessment "conforms" $(+)$, "does not conform" (-), "mixed assessment" $(+/-)$, or "incomparable" (0) for each functional DT component depending on the compatibility assessment $v_{q_{1} n_{1}}$ and $v_{q_{2} n_{2}}$ for the concrete realization of the component $c_{t}$ from OICA.

Defining these assessments as the meanings of the function $F$ at the initial stage of applying OIVM models requires the "manual" assessment by experts in different subject domains and completing continuous extensions of the $\mathrm{SH}$ dimension by descriptions of new kinds, forms of interest, and metrics for the specific values. Such extensions are considered to be knowledge accumulation for further raising the level of function $F$ calculation automation, $\mathrm{EE}$ and risk management enhancement.

Development of relations of order in OIES dimensions. It is recommended to develop the metrics scales of values realization levels so that they establish relations of order in OIES dimensions based on ordering the levels of such a scale. It is not always possible to determine such an order in all situations, or only for limited conditions of the specific task, but this enables measuring a relative distance from one value to another or to the reference value. The author and his colleagues have experience in such projects $[29 ; 30]$ successfully employed in practice [31;32].

Example: the scales of realization levels of values-tools as IT-specialists' abilities [30] such as "responsibility for the job," "ability to work autonomously," and others were developed for representation of abilities realization levels which are the values both for an individual employee and an enterprise as a whole.

General conclusion and further studies. The system of requirements $\mathrm{R} 1-\mathrm{R} 9$ is regarded as the primary result of this study. Implementing these requirements in the suggested OEVS and OIVM structures is only one possible versionSupport of openness of the models included in the approach "values-directed enterprise engineering" provides the basis for enriching different EE methods to a certain degree based on the values in different interpretations.

At the same time, the presented approach in its primary fragments (values models structures, the principle of defining order relations in OEVS, and metrics structure of values realization levels) have already been employed in practice, for example, in the project for assessing IT-specialists' competencies as values, which confirms the feasibility of the suggested approach.

Analysis of the values models structures and experience of their use demonstrates that OIVM formalizing should be combined with accumulating knowledge about representations of actual values forms and their realization levels. This, in particular, will enable developing more enhanced systems of intellectual program agents supporting meaningful decisions in the areas of multi-agent enterprises engineering and continuous risky situations monitoring. On the whole, using knowledge about values in solving an extending range of business tasks and the suggested approach "Values-directed enterprise engineering" will facilitate enterprises sustainable development under digital economy conditions. This development is becoming more attainable due to the coverage of all business areas and enterprise components with development methods directed by values at the fundamental level and in the dynamic regime. 


\section{References}

1. IBRD (2016) World development report 2016: Digital dividends. Washington: International Bank for Reconstruction and Development.

2. Alderman L. (2017) Uber dealt setback after European Court rules it is a taxi service. The New York Times, 20 December 2017.

3. Pombinho J., Aveiro D., Tribolet J. (2012) Towards value-oriented enterprise engineering - Relativity in service system networks. Knowledge and Technologies in Innovative Information Systems. Proceedings of the 7th Mediterranean Conference on Information Systems (MCIS 2012). Guimaraes, Portugal, 8-10 September 2012. Lecture Notes in Business Information Processing, vol. 129, pp. 113-124.

4. Golnam A., Viswanathan V., Moser C.I., Ritala P., Wegmann A. (2014) Designing value-oriented service systems by value map. Proceedings of the International Symposium on Business Modeling and Software Design (BMSD 2013). Noordwijkerhout, The Netherlands, 8-10 July 2013. Lecture Notes in Business Information Processing, vol. 173, pp. 150-173.

5. Gilding P., Hogarth M., Reed D. (2002) Single bottom line sustainability. How a value centered approach to corporate sustainability can pay off for shareholders and society. Sydney, Australia: Ecos Corporation.

6. Ramamoorti S., Watson M.W., Zabel M. (2008) Engineering value into enterprise risk management. Internal Auditor, October 2008, pp. 53-59.

7. DeLozier S., Rhodes M.G. (2015) The impact of value-directed remembering on the own-race bias. Acta Psychologica, no. 154, pp. 62-68.

8. Castel A.D., Benjamin A.S., Craik F.I.M., Watkins M.J. (2002) The effects of aging on selectivity and control in short-term recall. Memory \& Cognition, vol. 30, no. 7, pp. 1078-1085.

9. Zinder E.Z. (2016) Expanding enterprise engineering paradigm. Business Informatics, no. 4 (38), pp. 7-18.

10. World Economic Forum (2018) The global risks report 2018. 13th edition. Geneva, Switzerland: World Economic Forum.

11. Weizsacker E.U., Wijkman A. (2018) Come on! Capitalism, short-termism, population and the destruction of the planet. A report to the Club of Rome. NY: Springer.

12. Zinder E.Z. (2017) Upravlenie balansom strategicheskogo i takticheskogo v realizatsii tsifrovykh predpriyatii i elektronnykh pravitel'stv [Managing the balance of strategy and tactics in digital enterprises and electronic governments implementation]. Information Society, no. 2, pp. 9-22 (in Russian).

13. Zinder E.Z., Yunatova I.G. (2017) Digital economy and knowledge barriers: Their origin and dealing with them. Proceedings of Digital Transformation and Global Society: Second International Conference (DTGS 2017). St. Petersburg, Russia, 21-23 June 2017, pp. 445-463.

14. Zinder E.Z. (2018) Strategicheskie "tsifrovye" riski predpriyatii i obshchestva. Dvizhenie k nepreryvnomu risk-menedzhmentu [Strategic "digital" risks of enterprises and the society: Movement to continuous risk management]. Proceedings of the XXI Russian Scientific Conference on Enterprise Engineering and Knowledge Management (EE\&KM-2018). Moscow, 26-28 April 2018. Moscow: REU, vol. 1, pp. 276-281 (in Russian).

15. Humanitarian Technologies (2018) Aksiologiya [Axiology]. Available at: http://gtmarket.ru/concepts/ 6894 (accessed 06 July 2018) (in Russian).

16. Solomanidina T.O. (2007) Organizatsionnaya kul'tura kompanii [Organizational culture of a company]. Moscow: INFRA-M (in Russian).

17. Olsen E. (2002) Rethinking value-based management. Handbook of business strategy, pp. 286-301. Available at: https://www.bcg.com/documents/file14651.pdf (accessed 06 July 2018).

18. Tang D. (2017) What is value based management (VBM)? Flevy Blog. 23 March 2017. Available at: http://flevy.com/blog/what-is-value-based-management-vbm/ (accessed 06 July 2018).

19. Pombinho J.P.M. (2015) Value-oriented enterprise transformation: Design and engineering of value networks. PhD Thesis. Lisboa: Universidade de Lisboa.

20. Jaackson K. (2010) Management by values: Are some values better than others? Journal of Management Development, vol. 29, no. 9, pp. 795-806. 
21. Dolan S.L., Altman Y. (2012) Managing by values: The leadership spirituality connection. People \& Strategy Journal, vol. 35, no. 4, pp. 20-26.

22. Institute of Philosophy RAS (2018) Aksiologiya [Axiology]. Available at: https://iphlib.ru/greenstone3/ library/collection/newphilenc/document/HASH0147b7e8f087b539ec51af47 (accessed 06 July 2018) (in Russian).

23. Humanitarian Technologies (2018) Tsennost' [Value]. Available at: http://gtmarket.ru/concepts/6895 (accessed 06 July 2018) (in Russian).

24. Sitkevich N.V. (2011) Osobennosti transformatsii nravstvennykh tsennostei v usloviyakh informatsionnogo obshchestva: etiko-filosofskii analiz [Particularities of transformation of moral values in the conditions of information society: ethical and philosophical analysis]. PhD Thesis. Novomoskovsk: D. Mendeleev University of Chemical Technology of Russia (in Russian).

25. Maslow A.H. (1962) Toward a psychology of being. Princeton, USA: Van Nostrand.

26. Graves C.W. (1970) Levels of existence: An open system theory of values. Journal of Humanistic Psychology, vol. 10, no. 2, pp. 131-155.

27. Schwartz S.H. (2012) An overview of the Schwartz theory of basic values. Online Readings in Psychology and Culture, vol. 2, no. 1. Available at: https://scholarworks.gvsu.edu/orpc/vol2/iss1/11/ (accessed 05 February 2018).

28. McLeod S. (2018) Maslow's hierarchy of needs. Available at: www.simplypsychology.org/maslow.html (accessed 05 February 2018).

29. Zinder E.Z., Telnov Yu.F., Yunatova I.G. (2011) Metodika postroeniya modeli kompetentsii na osnove professional'nykh standartov v oblasti IKT dlya sozdaniya programm dopolnitel'nogo professional'nogo obrazovaniya [The methodology of competence model design based on professional standards in ICT area for creation of the additional professional educational programs]. Economics, Statistics and Informatics. Vestnik UMO, no. 6, pp. 112-118 (in Russian).

30. Zinder E.Z., Yunatova I.G. (2012) Sistema metrik i otsenochnykh shkal znanii, umenii i sposobnostei v normalizovannoi modeli kompetentsii primenitel'no k sfere IKT [The system of metrices and evaluative scales of knowledge, skills and abilities in the normalized model of competences applied to the ICT area]. Proceedings of the XV Conference on Business Processes Reengineering and Knowledge Management Systems (BPR\&KMS-2012). Moscow, 23-25 April 2012. Moscow: MESI, vol. 1, pp. 85-89 (in Russian).

31. Guzik S.V., Zinder E.Z., Yunatova I.G. (2013) Novaya paradigma inzhiniringa predpriyatiya i upravlenie sootvetstviem mezhdu rabochimi protsessami i kompetentnost'yu ikh ispolnitelei [A new paradigm of enterprise engineering and management of compliance between

working processes and competency of their executers]. Proceedings of the XVI Conference on Enterprise Engineering and Knowledge

Management (EE\& KM-2013). Moscow, 25-26 April 2013. Moscow: MESI, pp. 90-100 (in Russian).

32. Zinder E.Z., Yunatova I.G. (2013) Conceptual framework, models, and methods of knowledge acquisition and management for competency management in various areas. Proceedings of the 4th International Conference on Knowledge Engineering and the Semantic Web (KESW 2013). St. Petersburg, Russia, 7-9 October 2013 (eds. P. Klinov, D. Mouromtsev). Berlin, Heidelberg: Springer, vol. 394, pp. $228-241$. 